Orientated Psychiatric Services (1988) emphasised the need for more community based training experience, including "working as a member of a nonhierarchical multi-disciplinary team" and "being an active member of the clinical multi-disciplinary team". It was seen as important by many of those surveyed to gain special training in management skills. This latter point was emphasised by the Working Party on Management Training (1985) and they further emphasised that Consultant Appointments Committees should be asked to evaluate the training experience of applicants.

Enabling future consultants to understand their management role within the network of relationships that make up a clinical team will enable them to act effectively as leaders, where it is relevant, and also to respond to other members' appropriate managerial roles. Learning how to share a common purpose, that of the best possible patient care, leads to an increased sense of cohesion in the team and a sense of self-esteem and worth in every member of that group. Neglect of these issues will lead to increasing disaffection by the other workers and isolation of the psychiatric profession.

\section{References}

BHUGR, D. (1987) The public image of psychiatry. Bulletin of the Royal College of Psychiatrists, 11, 105.

GolDBERG, D. (1986) quoted in BIRLEY, J. L. T. (1987)

Psychiatrists and psychologists: working together for planning services in the post-Griffiths era. Bulletin of the Royal College of Psychiatrists, 11, 211.

HARDWICK, P. (1983) Consultant at large: the first year reviewed. Bulletin of the Royal College of Psychiatrists, 7, 26-28.

HARRIS, V. (1987) Community psychiatry! Bulletin of the Royal College of Psychiatrists, 11, 274-275.

McKrown, T. (1979) In The Role of Medicine, pp. 131-135. Oxford: Blackwell.

Royal College of Psychiatrists (1977) The responsibilities of consultants in psychiatry within the National Health Service. News and Notes, p. 4-7.

(1985) Report of the Working Party on Management Training. Bulletin of the Royal College of Psychiatrists, 9, 84-85.

(1986) Criteria for consultant posts in psychiatry. Bulletin of the Royal College of Psychiatrists, 10,324-325.

-; SECTION fOR SOCIAL AND COMmUNITY PSYCHIATRY (1987) Recommendations on training in social and community psychiatry in SHO/Registrar training schemes. Bulletin of the Royal College of Psychiatrists, 11, 213.

SCOTT, J. \& WEBB, T. (1988) Training implications of the shift to community-orientated psychiatric services, Collegiate Trainees' Committee Working Party Report. Bulletin of the Royal College of Psychiatrists, 12, 151-153.

SEDGWICK, P. (1983) The fate of psychiatry in the new populism. Bulletin of the Royal College of Psychiatrists, 7, 22-25.

WATTS, F. N. \& BENNETT, D. H. (1983) Management of the staff team. In Theory and Practice of Psychiatric Rehabilitation (eds. Watts, F. N. and Bennett, D. H.). Chichester: Wiley.

A full list of references is available from the author on request.

\title{
Befriending: cost-effective community care
}

\author{
D. G. Kingdon, Consultant Psychiatrist; D. TuRkington, Senior Registrar \\ (correspondence); J. Coluss, Development Officer; Department of Psychiatry, \\ Bassetlaw District General Hospital, Worksop, Nottinghamshire; and M. JUDD, \\ Volunteer Coordinator, Bassetlaw MIND
}

In a survey of district plans for Mental Health services (Kingdon, 1988) befriending schemes, where volunteers are recruited to visit isolated and lonely users of psychiatric services, were planned or in existence in 14 of the 127 districts who responded. However, lists of the components of a comprehensive community service (MIND, 1983) and Hirsch
(1988) surprisingly do not include references to such schemes, although Griffiths (1988) alludes to them in his recent report. There are moreover no reports in the psychiatric literature of such enterprises. The scheme established by MIND in Bassetlaw (population $(103,000)$ is therefore described. 


\section{The development of the scheme}

In 1986, a full-time volunteer co-ordinator was appointed by MIND using funds from the DHSS 'Opportunities for Volunteering' scheme to recruit volunteers through advertisement in the local press and by 'word of mouth'. Over 100 responses were received. Thirty-nine followed this up and attended training schemes involving ten evening sessions in different locations around the district to which members of the district mental health team contributed. Referrals were elicited from local agencies and the co-ordinator began the process of matching clients to volunteers. The yearly cost of the scheme (1988 prices) is estimated as being: administration including volunteer expenses and publicity $(£ 5,600)$ and staff costs $(£ 9,400)$, totalling $£ 15,000$ (approximately the cost of one community psychiatric nurse or social worker).

\section{The volunteers}

Following the training courses, 31 volunteers took up 'active service' and contributed to befriending clients in their homes, or by engaging in activities such as attending local leisure centres together. They also become involved in support groups, running a 'drop in' cafe' and serving on MIND committees. Their ages ranged from 18 to 59 , with eight males and 22 females. Some had had previous personal experience of psychiatric services and a number of these commented on this as being a practical way of giving something back after being helped themselves. References were requested and followed up and insurance arrangements made. Regular support and supervision was given and considered to be of fundamental importance to the success of the scheme by all concerned with it.

\section{The 'befriended'}

Over a two year period, 46 referrals were received directly from psychiatrists (4), from social workers (14), community psychiatric nurses (14), day centre staff (7), women's refuge (2), and by self-referral (5). Ages ranged from 19 to 64, 12 male and 34 female. Diagnoses of those referred by psychiatrically trained staff included schizophrenia (8), manic depressive psychosis (2), depressive neurosis (11), anxiety states (8), and dependent personality disorder (3). Selection criteria were based on a client's willingness to accept a befriender, their self-perceived social isolation and also consideration of their clinical state. Active psychotic symptoms were usually considered a contraindication to befriending. Inpatients were not included as direct arrangements for befriending of long-stay patients in the district's hospital hostels had been made with local schools and colleges under the supervision of health service staff.

\section{Comment}

The scheme described has been successful with clients and referring agencies. It serves a number of functions in a community service. Firstly, it provides befriending for many users of psychiatric services who, because of problems of loneliness, present with symptoms of anxiety or depression. Their presence in general practice surgeries, psychiatric out-patient clinics and on social worker and community nurse caseloads is well recognised and leads to inefficient use of professional time. Professionals cannot befriend as well as volunteers who form part of the client's community and can assist in their integrating in it. Excessive 'face to face' contact with relatives, known to increase the risk of relapse in schizophrenia (Leff \& Wing, 1971) can be reduced. Patients who may not accept day care may accept befriending. Secondly, involvement of volunteers in mental health projects is an effective way of disseminating information about services through the community and assists in combatting stigmatisation. Thirdly, involvement in volunteer training schemes can be profoundly effective in educating mental health professionals about the concerns and apprehensions that their community has about the services we think they need.

\section{Acknowledgements}

We thank all the volunteers who made the scheme possible.

\section{References}

Griffiths, R. (1988) Community Care: Agenda for Action. London: HMSO.

HIRSCH, S. R. (1988) Psychiatric Beds and Resources: Factors Influencing Bed Use and Service Planning. London: Gaskell (Royal College of Psychiatrists):

KINGDON, D. G. (1989) Mental health services: Results of a survey of English district plans. Psychiatric Bulletin of the Royal College of Psychiatrists, 13, 77-78.

LEFF, J. P. \& WING, J. K. (1971) Trial and maintenance therapy in schizophrenia. British Medical Journal, 3, 599-604.

MIND (1983) Common Concern. London: MIND Publications. 